\title{
Coulisses
}

Revue de théâtre

7| Printemps 1993

Varia

\section{Oscar Milosz ou la Lituanie au cœur de l'Europe}

\section{Geneviève Druckute}

\section{OpenEdition}

Journals

Édition électronique

URL : http://journals.openedition.org/coulisses/2242

DOI : $10.4000 /$ coulisses. 2242

ISSN : 2546-9460

\section{Éditeur}

Presses universitaires de Franche-Comté

\section{Édition imprimée}

Date de publication : 1 avril 1993

Pagination : $32-35$

ISSN : 1150-594X

\section{Référence électronique}

Geneviève Druckute, « Oscar Milosz ou la Lituanie au cœur de l'Europe », Coulisses [En ligne], 7|

Printemps 1993, mis en ligne le 15 mars 2019, consulté le 22 octobre 2019. URL : http://

journals.openedition.org/coulisses/2242 ; DOI : 10.4000/coulisses.2242

Ce document a été généré automatiquement le 22 octobre 2019

Coulisses 


\title{
Oscar Milosz ou la Lituanie au cœur de l'Europe
}

\author{
Geneviève Druckute
}

Oscar Milosz (1877-1939) est un des grands écrivains français du XXème siècle, malheureusement peu connu du large public. Ce poète, auteur dramatique, romaniste, philosophe et mystique, est d'origine lituanienne. Il est né dans une vieille famille noble à Czereïa, province de Mohilev, dans la Lituanie historique; ce territoire appartient maintenant à la Biélorussie. Venu à Paris à l'âge de douze ans, pour faire ses études au lycée Janson-de-Sailly, O. Milosz a vécu en France pendant toute sa vie, recevant en 1931 la nationalité française.

O. Milosz n'a jamais oublié sa première patrie, la Lituanie, « un pays où toutes choses ont la couleur éteinte du souvenir $»^{1}$. Il a toujours soutenu la lutte pour l'indépendance; de 1920 à 1925 il a été Ministre de Lituanie en France. O. Milosz a donné des conférences, écrit des articles sur son pays d'origine. Il est connu aussi comme traducteur du folklore lituanien en français. Il a publié deux recueils ${ }^{2}$ de contes lituaniens : Contes et fabliaux de la Vieille Lithuanie (1930) et Contes lithuaniens de ma mère l'Oye (1933), et un petit recueil d'une trentaine de chansons populaires Daïnos (1928) ${ }^{3}$. 


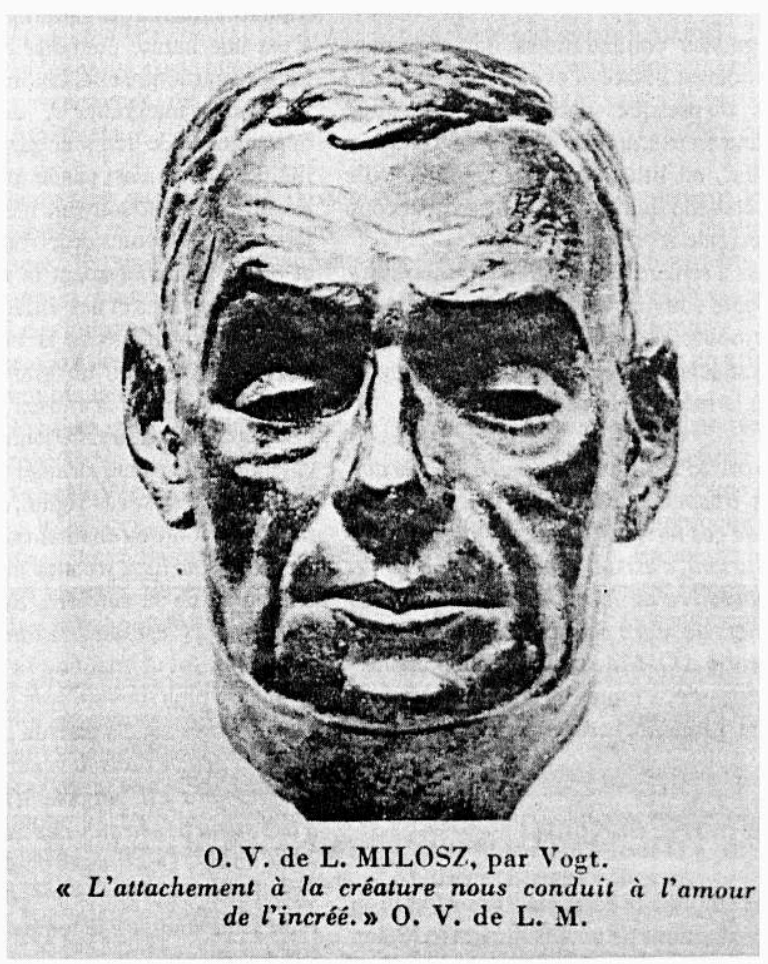

\section{La Lituanie, Berceau de l'Europe}

O. Milosz avait pour but de faire connaître la Lituanie aux Français et aux autres peuples de l'Europe Occidentale. Pour lui, la Lituanie est l'ancien berceau des Européens. Il a exprimé cette idée pour la première fois dans la Conférence du 29 mars 1919 donnée à la Salle de Géographie à Paris.

Si donc je quitte ma haute solitude pour vous entretenir de la Lituanie, c'est que la contrée merveilleuse qui m'a donné toute son âme n'est pas seulement ma patrie à moi, mais aussi votre patrie à vous. Oui, femmes et hommes d'Occident, je vous parle de votre antique patrie. Oui, filles et fils de la race indo-européenne, je vous parle de votre berceau. ${ }^{4}$

Dans l'essai Les origines de la nation lithuanienne, paru en 1937, ce point de vue a reçu une forme plus détaillée, plus concrète et s'est revêtu d'un langage scientifique. Les Lituaniens comme les Basques sont les habitants les plus anciens de l'Europe ayant une origine commune, c'est-à-dire ibérique. $\mathrm{O}$. Milosz, pour prouver sa théorie, s'appuie sur des données linguistiques, anthropologiques, folkloriques, ethnographiques, héraldiques. Il souligne que le lituanien et le sanscrit sont des langues très proches; d'autre part, le lituanien et le basque sont les langues les plus anciennes des Aryens en Europe. Pour la linguistique comparative, le lituanien joue un très grand rôle. Dans les travaux linguistiques,

consacrés à la formation et à l'évolution de l'indo-européen commun, langue mère de l'Espagne centrale et orientale, d'où sont sortis le grec, le latin, et les idiomes germaniques et slaves, (...) le parler lithuanien constitue un document de tout premier ordre. ${ }^{5}$ 
Les données anthropologiques laissent croire que l'une des caractéristiques principales des Lituaniens est leur haute stature et la dolichocéphalie, c'est-à-dire, les crânes d'une forme allongée, bien qu'ils soient entourés d'autres peuples brachycéphales et de petite taille. Ce phénomène est propre aussi aux Basques, et 0 . Milosz y voit une heureuse coïncidence.

4 Le rapprochement des cultures et des folklores lituanien et basque, permet de constater d'autres analogies, le culte du serpent et l'adoration de certains arbres, comme le chêne. Les Laumés, sorte de fées lituaniennes, sont pareilles aux Lamias ou Lamigna basques, et ces personnages féminins folkloriques proviennent des sorcières ibères préhistoriques.

5 Le refrain dan dan dalidan répété très souvent dans des chansons lituaniennes populaires et privé de tout sens s'explique facilement par le refrain basque din dan baledan qui renvoie à une superstition préhistorique attachée à la corde du pendu. L'auteur de l'essai rapporte l'apparition de ce refrain au début du christianisme.

6 Beaucoup de peuples européens y compris le lituanien et le basque reprennent le conte $\mathrm{du}$ Petit Poucet mais c'est seulement le lituanien qui donne l'explication du mot poucet ${ }^{6}$ : ce personnage est le propre pouce coupé de la main gauche de la mère.

7 Les linguistes comparatistes ont découvert beaucoup de mots en lituanien et en grec ancien qui ont les mêmes, ou presque, sonorité et signification. O. Milosz donne en exemple le mot polis en grec, et le mot pilis, en lituanien, qui signifie « ville forte ». Il est persuadé que ce mot comme beaucoup d'autres est d'origine ibérique.

8 O. Milosz a remarqué que l'héraldique européenne représente souvent le Cavalier et le Cheval Blancs. Les armoiries lituaniennes en portent aussi. O. Milosz les rattachent ainsi que le Cheval blanc de l'Apocalypse à la même origine ibérique.

9 Ainsi le sol de la Lituanie et de l'Espagne

doit renfermer des trésors scientifiques inestimables... L'exploration de ces terres illustres est à peine commencée. Et pourtant, c'est dans leurs profondeurs et non dans la poussière du lointain Orient que nous attendent les clefs de notre passé et de notre avenir.

Cette théorie d'O.Milosz, considérée maintenant comme dépassée, a toutefois contribué à attirer l'attention sur la Lituanie, berceau fantasmatique de l'Europe.

\section{La Lituanie, patrie du conte}

O. Milosz emploie le terme de transcription en parlant de ses traductions de contes lituaniens. Selon lui, le mot traduction est vide de sens quand il s'agit d'art. Celui de version conviendrait mieux mais tous les contes sont déjà des versions. $\mathrm{O}$. Milosz choisit donc le terme de transcription et compare le travail de transcripteur à celui du compositeur qui prenant une mélodie populaire, compose un arrangement qui tout en lui conservant sa couleur et son rythme transmet en même temps ses sentiments, ses émotions, ses idées propres.

Dans les Contes d'O. Milosz la Lituanie est vue à vol d'oiseau ; c'est une vision émanant des souvenirs de l'auteur. Il présente aux lecteurs une double image de sa terre natale. D'une part, c'est une terre mythique, une sorte de "terre promise», un pays des 
mystères et des miracles; d'autre part, la Lituanie se trouve au cœur de l'Europe, et tout ce qui se trouve dans les pays européens est propre à la Lituanie.

Le côté mystérieux et mythique, c'est tout d'abord, la nature qui garde toute sa fraîcheur primitive. C'est une nature éternelle et sacrée. Le temps est impuissant contre elle. Les humains et les animaux en font partie intégrante et occupent une place bien déterminée. Ce lien leur garantit harmonie et stabilité. L'homme n'est pas le maitre tout-puissant de la nature ; elle est souvent incompréhensible, sévère, fait peur. Les contes décrivent beaucoup de paysages et plus particulièrement la forêt. Elle se trouve en dehors des villes et des villages où habitent les gens, elle reste en marge de la vie, inconnue, étrangère, sauvage. Elle joue un grand rôle dans la vie des hommes. Toutes les choses les plus extraordinaires peuvent s'y produire. Le jeune et brave soldat Jonelis entend soudain une étrange chanson chantée par un oiseau. C'est sa sœur Siguté, enchantée par leur belle-mère, qui conte en chantant sa triste histoire. La forêt va aider Jonelis à trouver une vengeance. Après le châtiment de la sorcière, Siguté reprend sa forme humaine ${ }^{7}$. C'est dans la forêt que le petit Hérisson obtient du roi la main de sa fille ${ }^{8}$. Les arbres mentionnés le plus souvent sont le chêne, le bouleau et le sapin, arbres sacrés dans la mythologie lituanienne. «La clef grince dans la vénérable serrure, il entre.... La chambre est baignée d'une lune d'automne et d'une odeur pénétrante des siècles" (L'Empereur Jean-sans âme) ${ }^{9}$. Des images poétiques de l'automne sont fréquentes dans les contes d'O. Milosz, saison qui représente toujours le temps de la maturité.

14 L'eau, et surtout la mer, est une autre source de mystères. Pour l'homme, la mer, comme la forêt, est un monde à part. Il lui est interdit de la connaître. Eglé, fille d'un homme, apprend les secrets de la mer grâce à l'amour. Devenue femme du roi des serpents, elle découvre la vie sous-marine :

L'on cingla vers une île où le jeune ophidien possédait un château construit sous la vague. C'est là que fut célébré le mariage. La demeure du serpent n'était comme luimême et son entourage, que miroitement, splendeur et doux murmures ${ }^{10}$

"La reine des Serpents ", une simple servante est initiée aux secrets grâce à sa bonté : elle sauve de la mort un gros crapaud qui est en vérité le roi des grenouilles et des rainettes :

Dans le brouillard d'argent de plus en plus épais, la jeune fille réglait sa marche sur les mouvements de son guide pansu mais singulièrement agile. Après plus d'une heure de cet exercice, elle s'aperçut tout à coup qu'elle ne rampait plus mais nageait comme un vrai grenouillon dans les eaux étincelantes de lune d'un grand lac fort voisin du ciel ${ }^{11}$

La nature lituanienne est assez fantastique: on y trouve de hautes montagnes, de grands fleuves exotiques, des îles inhabitées.

Mais cette nature n'est qu'un fond où agissent les personnages des contes. Les plus actifs sont souvent les animaux sauvages. Ils sont très indépendants, infiniment plus forts et plus intelligents que les hommes. Les liens des animaux avec la nature sont conservés alors que ceux des hommes sont rompus. Ce n'est qu'en communiquant avec les animaux que l'homme devient plus sage, plus puissant, qu'en apprenant leur langage qu'il découvre ce qui est caché à ses yeux. Grâce à l'oiseau Vérité, le roi retrouve ses deux enfants perdus longtemps auparavant. ${ }^{12}$.

Les animaux sont des intermédiaires entre les forces divines et le monde humain. Ils ont le pouvoir de ressusciter les morts. Quand Siguté a été brûlée par sa belle-mère, 
[la vache noire], en passant près du poteau, [...] reconnut à l'odeur les restes de son amie. Elle en approcha son museau et souffla de toutes ses forces : un canard aux couleurs éblouissantes s'envola aussitôt des cendres vers le ciel ${ }^{13}$ préhistoriques, est complètement intégrée à l'Europe. Les rois lituaniens habitent dans de magnifiques palais de styles divers, ils donnent des bals et des fêtes, ils luttent contre «les chevaliers Teutoniques de Prusse », lisent les romans de Monsieur Arouet de Voltaire, discutent Dante Alighieri, du grand Will, du divin Wolfang de Francfort, de Villon, et le font «à la dernière mode de Versailles. » Il y a des princes qui s'écrient : « je suis républicain, moi! mort aux tyrans! ». Les princesses apprennent « do, ré, mi, fa, sol ». Des prêtres et des religieux «ânonnent bonjour et bonsoir en latin » et s'adressent souvent à la Vierge et aux Saints. Des bourgeois pensent à la «valeur qui se laissait difficilement exprimer en dollars ou en livres" et s'occupent de l'agrandissement de la maison-mère et de la création d'une succursale à Memel. La politique est très active : le roi s'entretient souvent avec son ministre des relations extérieures et parfois il doit répondre aux ultimatums. En Lituanie on boit du « vin de France ».

21 L'action se déplace facilement de Lituanie «à Paris » ou «aux Etats-Unis, pays de liberté et surtout de pensée». Les brigands lituaniens parlent comme des voleurs français : « Faudrait compter le pèze et puis aller roupiller. Ma toquante. - Ta gueule !» ${ }^{14}$. Ce procédé inattendu donne un effet ironique.

22 Il est difficile de comparer les contes d'O. Milosz aux contes populaires lituaniens. Il n'en a gardé que le prétexte. Par un style, et une poésie, qui lui sont propres. O. Milosz a su rapprocher le folklore lituanien de l'esprit européen. En même temps, l'image de la Lituanie que le lecteur se fait en lisant ses contes, est celle des idées et des sentiments de l'auteur Oscar Milosz.

\section{NOTES}

1. Euvres Complètes, Tome 13, p. 32.

Les œuvres complètes d'O. Milosz sont publiées aux éditions André Silvaire.

2. CEuvres Complètes, Tome 6.

3. Euvres Complètes, Tome 9.

4. Euvres Complètes, Tome 13, p. 27.

5. Euvres Complètes, Tome 9, p. 201.

6. CEuvres Complètes, Tome 9.

Coulisses, 7 | Printemps 1993 
7. In Siguté. CEuvres Complètes, Tome 9.

8. In Le Hérisson. Euvres Complètes, Tome 9.

9. Euvres Complètes, Tome 9, p. 97.

10. In La Reine des Serpents. Euvres Complètes, Tome 9, p. 129.

11. In Le Crapaud. Cuvres Complètes, Tome 9, p. 83.

12. In Trois Cheveux d'or et trois petites étoiles.

13. In Siguté. CEuvres Complètes, Tome 9, p. 31-32.

14. Euvres Complètes, Tome 6, p. 224.

\section{AUTEUR}

\section{GENEVIÈVE DRUCKUTE}

Professeur de Littérature française à l'université de Vilnius. Prépare sa thèse sur O. Milosz. 